\section{EL ABUSO DE CONFIANZA Y EL PECULADO EN LA RESPONSABILIDAD PENAL EMPRESARIAL: LA RESPONSABILIDAD PENAL POR ADMINISTRACIÓN DE FONDOS PARAFISCALES EN LAS E.P.S. EN COLOMBIA*}

\section{Jorge Arturo Abello Gual ${ }^{* *}$}

Fecha de recepción: 8 de Octubre de 2010

Fecha de aceptación: 30 de Noviembre de 2010 Artículo de Reflexión

\section{Resumen}

En el presente trabajo se analizará, si los gerentes y trabajadores de una E.P.S., que se apropien de los fondos parafiscales que ésta última recibe para satisfacer las necesidades de salud de sus afiliados, son responsables del delito de peculado o del delito de abuso de confianza calificado.

\section{Palabras clave}

Fondos parafiscales, seguridad social, Empresa Promotora de Salud (E.P.S.), peculado, abuso de confianza calificado, responsabilidad empresarial.
* El proyecto de investigación del cual es producto este documento ha sido financiado por la Fundación Politécnico Grancolombiano, mediante el contrato de investigación 2010-DI-FCS-DJG-BC-4, del 14 de diciembre de 2009.

** Abogado y especialista de derecho penal de la Universidad del Norte. Candidato a magíster de la Universidad de los Andes. Profesor e investigador de la Facultad de Ciencias sociales del Politécnico Grancolombiano. georabello@hotmail.com

\section{THE ABUSE OF TRUST AND EMBEZZLEMENT IN THE CRIMINAL RESPONSIBILITY: CORPORATE CRIMINAL LIABILITY FOR ADMINISTRATION OF PARAFISCAL FUNDS IN THE E. P.S. IN COLOMBIA}

\begin{abstract}
In this paper we analyze, if managers and workers in an Health Promoting Company (EPS), take ownership of the funds received parafiscal latter to meet the health needs of their members, are responsible for the crime of embezzlement, crime or abuse qualified trust.
\end{abstract}

\section{Key words}

Para-fiscal funds, social security, Health Promoting Company (EPS), embezzlement, breach of trust, corporate responsibility.

\section{ANALISIS Y DELIMITACIÓN DEL PROBLEMA A TRATAR}

El tema que se desarrollará en este trabajo es sobre la responsabilidad penal de los gerentes, funcionarios directivos y empleados de una E.P.S., por la pérdida de los recursos que deben administrar provenientes de los aportes parafiscales a la Seguridad Social que realizan todos los afiliados. La investigación estuvo enfocada en analizar una aparente contradicción entre los tipos penales aplicables a este tipo de hechos, esto es el peculado y el abuso de confianza calificado, que abarcan en su descripción típica la apropiación que puede llevar a cabo una persona que administre fondos parafiscales destinados a la seguridad social.

Para comenzar el análisis del tema planteado, se citará las disposiciones legales que contienen los tipos penales del peculado y el abuso de confianza calificado, exaltando los apartes que incitan a una posible antinomia entre las dos normas, toda vez que parecen punir ambas el hecho de que un administrador o empleado se apropie de los fondos parafiscales destinados a 
la salud, que administra la E.P.S. para la cual trabajan:

Artículo 20. Servidores públicos. Para todos los efectos de la ley penal, son servidores públicos los miembros de las corporaciones públicas, los empleados y trabajadores del Estado y de sus entidades descentralizadas territorialmente y por servicios.

Para los mismos efectos se consideran servidores públicos los miembros de la fuerza pública, los particulares que ejerzan funciones públicas en forma permanente o transitoria, los funcionarios y trabajadores del Banco de la República, los integrantes de la Comisión Nacional Ciudadana para la Lucha contra la Corrupción y las personas que administren los recursos de que trata el Artículo 338 de la Constitución Política. (Negrillas fuera del texto)

Partiendo de lo anterior, el peculado se tipifica en el Código Penal de la siguiente manera:

Artículo 397. Peculado por apropiación. El servidor público que se apropie en provecho suyo o de un tercero de bienes del Estado o de empresas o instituciones en que éste tenga parte o de bienes $o$ fondos parafiscales, $o$ de bienes de particulares cuya administración, tenencia o custodia se le haya confiado por razón o con ocasión de sus funciones, incurrirá en prisión de seis (6) a quince (15) años, multa equivalente al valor de lo apropiado sin que supere el equivalente a cincuenta mil (50.000) salarios mínimos legales mensuales vigentes, e inhabilitación para el ejercicio de derechos y funciones públicas por el mismo término. (...) (Negrillas fuera del texto).

Por otra parte, el abuso de confianza se tipifica de la siguiente manera

Artículo 249. Abuso de confianza. El que se apropie en provecho suyo o de un tercero, de cosa mueble ajena, que se le haya confiado o entregado por un título no traslativo de dominio, incurrirá en prisión de uno (1) a cuatro (4) años y multa de diez (10) a doscientos (200) salarios mínimos legales mensuales vigentes.
La pena será de prisión de uno (1) a dos (2) años y multa hasta de diez (10) salarios minimos legales mensuales vigentes, cuando la cuantía no exceda de diez (10) salarios mínimos legales mensuales vigentes.

Si no hubiere apropiación sino uso indebido de la cosa con perjuicio de tercero, la pena se reducirá en la mitad.

Artículo 250. Abuso de confianza calificado. La pena será prisión de tres (3) a seis (6) años, y multa de treinta (30) a quinientos (500) salarios minimos legales mensuales vigentes si la conducta se cometiere:

1. Abusando de funciones discernidas, reconocidas o confiadas por autoridad pública.

2. En caso de depósito necesario.

3. Sobre bienes pertenecientes a empresas o instituciones en que el Estado tenga la totalidad o la mayor parte, o recibidos a cualquier título de éste.

4. Sobre bienes pertenecientes a asociaciones profesionales, civicas, sindicales, comunitarias, juveniles, benéficas o de utilidad común no gubernamentales.

Partiendo de la redacción de los tipos penales antes transcritos y los apartes puestos en negrillas, podemos plantear el problema que se generaría si surge la necesidad de iniciar un proceso penal por un hecho en el cual, un gerente o un trabajador de una E.P.S., se apropia de los fondos parafiscales recaudados de las diferentes empresas y afiliados del sistema general de seguridad social. Para iniciar una actuación penal en el caso citado, debemos definir si tendríamos que imputar dicha conducta a título de peculado o a título de abuso de confianza calificado. Y para ello se hace necesario tener claridad sobre una característica que diferencia el abuso de confianza calificado y el peculado, y es precisamente la calidad de servidor público, y los bienes protegidos por el delito de peculado ${ }^{1}$.

MOLINA ARRUBLA, Carlos Mario. Delitos Contra la Administración pública. Leyer. 4 edición. Bogotá. 2003 


\subsection{El carácter público de los fondos parafiscales}

En relación con los bienes, ya se ha establecido por parte de la Corte Suprema de Justicia que los parafiscales son recursos del Estado. Sobre el tema ha dicho la Corte Suprema de Justicia lo siguiente:

"Que los recursos como las cotizaciones para el sector salud son bienes parafiscales, pues son recursos captados del sector privado para ser reinvertidos para prestar el servicio de salud. Además, la Ley 828 de 2003, dispone que las contribuciones al Sistema de Seguridad Social son aportes parafiscales.

La contribución parafiscal se presenta cuando el Estado, en ejercicio de su deber de interventor en la economía, impone a los asociados una contribución para atender un fin de carácter económico y social, en este caso, cubrir las necesidades de salud de los colombianos. Por esta razón, aunque la contribución no entre al patrimonio de la Nación por su carácter especifico, no se puede negar que es un ingreso público por tener un carácter impositivo y por poseer como fin atender necesidades públicas ${ }^{2}$.

Según las características de la cotización en seguridad social, se trata de una típica contribución parafiscal, distinta de los impuestos y las tasas. En efecto, constituye un gravamen fruto de la soberania fiscal del Estado, que se cobra de manera obligatoria a un grupo de personas cuyas necesidades en salud se satisfacen con los recursos recaudados, pero que carece de una contraprestación equivalente al monto de la tarifa. Los recursos provenientes de la cotización de seguridad social no entran a engrosar las arcas del presupuesto Nacional, ya que se destinan a financiar el sistema general de seguridad social en salud.

Con base en lo anterior, es claro que el primer tema de exactitud por parte de la Sala aparece pacificamente resuelto por las fuentes normativas citadas, la jurisprudencia constitucional y la doctrina: los

2 QUERALT, Juan Martín, et al. Curso de Derecho Financiero y Tributario. Tecnos. 11 Edición. Madrid. 2000. p. 100 recursos o aportes a la seguridad social en salud, son de naturaleza parafiscal. Son tributos o bienes públicos, que pertenecen al Estado...”’.

\subsection{El carácter público de la función de administrar recursos públicos}

En segundo lugar, se ha establecido las E.P.S. al administrar los recursos públicos ejerce una función pública y ello permite la aplicación del Artículo 20 del C.P. "los particulares que ejerzan funciones públicas en forma permanente $\mathrm{o}$ transitoria".

Sin embargo, sobre este punto es necesario hacer algunas precisiones. La función pública, es una labor que no se comienza a ejercer de cualquier forma:

"En un Estado social y democrático de derecho no se accede de facto a las funciones públicas. Son las autoridades a través de sus competencias regladas las que atribuyen o encargan a un particular de una función pública. Es esto lo que se infiere del Artículo 123 de la Carta Politica, cuando preceptúa que los servidores públicos están al servicio del Estado y de la comunidad; ejercerán sus funciones en la forma prevista en la Constitución, la ley y el reglamento, $y$ agrega que la ley determinará el régimen aplicable a los particulares que temporalmente desempeñen funciones públicas y regularán su ejercicio"'.

De esta manera se aclara, que el ejercicio de una función pública, no es un acto de facto, y que requiere autorización legal o reglamentaria pues, como lo preceptúa la misma Constitución en el Artículo 122:

3 CORTE SUPREMA DE JUSTICIA. Sala Penal. Proceso Radicación 23982. Sentencia del 20 de Julio de 2007. M.P. Alvaro Orlando Pérez Pinzón.

4 En la sentencia C-866 de 1.999, la Corte Constitucional se ocupó de señalar los eventos en los cuales la constitución o la ley, directamente, impone a determinados particulares el cumplimiento de funciones públicas, la manera como se accede a ellas y el cumplimiento de precisos requisitos para poder predicar que se está cumpliendo esa función. 
"No habrá empleo público que no tenga funciones detalladas en ley o reglamento, y para proveer los de carácter remunerado se requiere que estén contemplados en la respectiva planta y previstos sus emolumentos en el presupuesto correspondiente".

A continuación citamos una sentencia de la Corte donde aclara que la función de recaudar y administrar los fondos parafiscales, es función pública:

"El recaudo de tributos públicos es una función pública asignada de manera principal por el numeral 20 del Artículo 189 de la Carta Politica al Presidente de la República, como Jefe de Gobierno y como Primera Autoridad Administrativa. La disposición dice asi:

Velar por la estricta recaudación y administración de las rentas y caudales públicos y decretar su inversión de acuerdo con las leyes.

El legislador puede distribuir esa competencia. Y lo hizo de manera puntual al crear el Sistema General de Seguridad Social en Salud en la ley 100 del 1993, modificada por la ley 1122 del 2007.

En ella se establece como una de las características del sistema, que: el recaudo de las cotizaciones será responsabilidad del Sistema General de Seguridad Social-Fondo de Solidaridad y Garantía, quien delegará en lo pertinente esta función en las Entidades Promotoras de Salud 5 .

Consecuente con esta asignación de competencias, la ley concreta que

Las Entidades Promotoras de Salud son las entidades responsables de la afiliación, y el registro de los afiliados y del recaudo de sus cotizaciones, por delegación del Fondo de Solidaridad y Garantía ${ }^{6}$.

\section{Artículo 156.d.}

6 Ver Artículo 170. La disposición se repite, como función específica de las Empresas o entidades promotoras de salud, en el Artículo 178 de la misma ley. Artículo 178. "FUNCIONES DE LAS ENTIDADES PROMOTORAS DE SALUD. Las Entidades Promotoras de Salud tendrán las siguientes funciones: Ser delegatarias del Fondo de Solidaridad y Garantía para la captación de los aportes de los afiliados al Sistema General de Seguridad Social en Salud".
Las Entidades Promotoras de Salud, por delegación legal, cumplen la función pública de recaudar los pagos que deben hacer los individuos y familias.

La ley reglamenta detalladamente el Sistema General de Seguridad Social en Salud: quiénes lo integran, qué condiciones son exigibles para entrar a ser parte de él, cuáles son las obligaciones de unos y otros, cuáles las competencias y cómo se cumplen.

Para cumplir la función pública de recaudar las cotizaciones, el Artículo 180 ibídem condiciona la autorización a las EPS a una serie de requisitos logísticos y humanos"

En concordancia con lo anterior, en los Artículos 170 y 178 de la Ley 100 de 1993 se establece expresamente que: "Las Entidades Promotoras de Salud, por delegación legal, cumplen función pública de recaudar los pagos que deben hacer los individuos y familias". En el mismo sentido, el Artículo 53 de la Ley 734 de 2002 estableció que cumplen funciones públicas quienes administren recursos del Estado. En igual sentido, se establece a través de las sentencias de la Corte Constitucional C-181 de 2002 y C-037 de 2003, que "la administración de recursos fiscales y parafiscales es, por definición, una función pública".

Por todo lo anterior, se llega a la siguiente conclusión: quién administra, o custodie bienes del Estado como son las contribuciones al sistema de seguridad social (fondos parafiscales) tiene la naturaleza de servidor público de conformidad con el Artículo 20 del Código Penal, y se le puede imputar el delito de peculado.

\subsection{La posición de la doctrina sobre la administración de fondos parafiscales por parte de las E.P.S.}

La anterior conclusión es compartida por los profesores Alfonso Gómez Méndez y Carlos Arturo Pavajeau, quienes establecen que las

7 CORTE SUPREMA DE JUSTICIA. Sala Penal. Proceso Radicación 23982. Sentencia del 20 de Julio de 2007. M.P. Álvaro Orlando Pérez Pinzón. 
E.P.S. "son particulares que ejercen funciones públicas no sólo porque así se ha calificado el recaudo sino también por tratarse de bienes parafiscales. Por tanto el delito en que incurren es en peculado por apropiación". Igualmente, consideran los citados autores, que allí "debe operar la noción de autoría por otro (Artículo 29 inciso 3 del Código Penal) por tanto, si el sujeto que delinque no tiene la calidad por cuanto la misma la tiene el ente colectivo - para el efecto la Entidad Promotora de Salud-, debe recibir la rebaja de pena de que da cuenta el inciso final del Artículo 30 idídem,..."9.

El profesor Carlos Mario Molina Arrubla también considera que se debe aplicar el peculado en estos eventos que venimos analizando por las siguientes razones:

"Alcanzaría el grado de servidor público -en determinación legal que no deja de ser bastante controvertible- aquella persona que administrase tales recursos (con lo cual, dicho sea de una vez, en el evento de apropiarse de los mismos, no estaría incurriendo en hurto sino en peculado), en atención a lo dispuesto en la parte final del inciso segundo del Artículo 20 del Código Penal"10.

El profesor Tocora por su parte, al comentar los eventos en que se configura el abuso de confianza, dispone que la primera causal (Abusando de funciones discernidas, reconocidas o confiadas por autoridad pública), evidencia que tanto el peculado y el abuso de confianza comparten las dos modalidades de conducta es decir, por apropiación y por uso, y que la calificación del sujeto activo como servidor público, no es suficiente para diferenciar una conducta de otra, pues

"las funciones discernidas, reconocidas o confiadas por autoridad pública, le dan a quien las obtiene

8 GÓMEZ MÉNDEZ, Alfonso, et al. Delitos contra la administración pública. Universidad Externado. 3 Edición. Bogotá. 2008. p. 97.

9 Ibídem.

10 MOLINA ARRUBLA, Carlos Mario. Delitos Contra la Administración pública. Ob. Cit. p. 52. categoría de servidor público, al tenor del Artículo 20 del Código Penal, que incluye en tal concepto, a los particulares que ejerzan funciones públicas en forma permanente o transitoria" ${ }^{11}$.

Continúa explicando el citado profesor que,

"la hipótesis del abuso de confianza calificado por la causal primera, le es aplicable por ejemplo, al depositario, a quien el secuestre le da a guardar los bienes confiados a él por el juez. En este caso, el depositario conserva su estatus de particular; no es servidor público, ni siquiera para el hecho de custodiar esos bienes. La agravante se le deduce por el hecho, de que el depósito le fue confiado por un servidor público, como quiera que el secuestre lo es para el efecto de cuidar esos bienes" $" 12$.

En relación con la causal tercera, el profesor anota que con la desaparición del peculado por extensión en la Ley 599 del $2000^{13}$, las conductas de apropiación realizadas por un particular

11 TOCORA, Luis Fernando. Derecho Penal Especial. Librería ediciones del profesional limitada. 11 Edición. Bogotá. 2009. p. 197.

12 Ibíd. p. 198.

13 Sobre el cambio legislativo, la Corte Suprema de Justicia en Sentencia del 20 de Julio de 2007. M.P. Álvaro Orlando Pérez Pinzón, ha señalado lo siguiente:

“...el Artículo 138.1 del decreto 100 de 1980 describe con exactitud el comportamiento del particular que se apropiaba de bienes del Estado, cuando media entre él y los bienes una relación jurídica, dada por la ley, de administración o de custodia, como es el caso del procesado.

Los Artículos 133 y 138 del Código Penal anterior sancionaban el apoderamiento por parte de funcionarios públicos y de particulares, respectivamente, de bienes pertenecientes al Estado, o de empresas o de instituciones en que éste tuviera la mayor parte, que estaban bajo su administración, tenencia o custodia.

Si el Artículo 138.1 se refería a bienes pertenecientes a instituciones o empresas en que el Estado tuviera la mayor parte, con mayor rigor la protección del tipo penal se extendia al bien que en su totalidad perteneciera al Estado, como ocurre con el Instituto del Seguro Social, que es una empresa social y comercial de éste .

El Artículo 250.3 de la ley 599 del 2000 retomó el comportamiento antes descrito y lo bautizó abuso de confianza calificado, pero precisó, para superar dudas, que la sanción procede cuando el bien afectado sea en su totalidad o en su mayor parte del Estado". 
sobre bienes de empresas o instituciones en el que el Estado la totalidad o la mayor parte, se enmarcan en el delito de abuso de confianza calificado, pues "debió considerarse que siendo un particular el sujeto activo de esta conducta, debia más bien tenerse como conducta ordinaria contra el patrimonio económico, aunque agravada por la titularidad pública o colectiva de los bienes, objeto material de la infracción" ${ }^{14}$.

\subsection{El abuso de confianza calificado fue el reemplazo del desaparecido peculado por extensión}

Para un mejor análisis de la supuesta convergencia del peculado y del abuso de confianza calificado, me permito citar la exposición de motivos de la Ley 599 de 2000, en la cual se cambió el tipo penal de peculado por extensión y se creó el abuso de confianza calificado:

"La exposición de motivos de la Ley 599 de 2000, contenida en el oficio del 4 de agosto de 1998, que el Fiscal General de la Nación envió al Presidente del Senado de la República, cuyo texto fue publicado por ese ente investigador, corrobora que el peculado por extensión definido en el Artículo 138 del anterior Código Penal, corresponde en la nueva normatividad al abuso de confianza. Textualmente se dijo $^{15}$ :

Se creó el delito de abuso de confianza calificado-art. 243-que además de contener las dos circunstancias de agravación punitiva señaladas en la vigente normativa para el abuso de confianza, se incluyó aquellos comportamientos que en la actualidad conforman el reato de peculado por extensión, pues sin duda alguna se trata de verdadero abuso de confianza defraudatorio del patrimonio económico del Estado sin relación alguna con la función pública. El llamado actualmente peculado por extensión se consagró como un tipo autónomo denominado

14 TOCORA, Luis Fernando. Derecho Penal Especial. Ob. Cit. p. 198.

15 Texto tomado de CORTE SUPREMA DE JUSTICIA. Sala Penal. Proceso No 20075. Sentencia de 6 de Agosto de 2003. M.P. Jorge Luis Quintero Milanés. abuso de confianza tal como se explicó en el acápite correspondiente" ${ }^{\prime \prime}$.

Es necesario por esta vía, acudir a la interpretación teleológica, atendiendo a la voluntad del legislador, quién en el año 2000 consideró conveniente derogar el delito del peculado por extensión y consagrar el abuso de confianza calificado. El intérprete podrá a través de la interpretación extensiva del Artículo 20 del C.P. y del Artículo 29 inciso 3 del mismo estatuto, imputar peculado en los casos analizados, pero con ello, está contrariando la intención inicial del legislador.

\subsection{Delimitacion del problema frente a otros eventos diferentes}

Una vez planteada la problemática y las posibles soluciones al tema, así como los antecedentes del abuso de confianza calificado, no sobra citar otra tesis aplicable al caso planteado, expuesta por la Corte Suprema de Justicia, que no tiene mucha sustentación, pues parece una apreciación aislada sobre la responsabilidad de funcionarios de las E.P.S., que no consignen las contribuciones del Sistema de Seguridad Social en Salud, pero que en todo caso hay que tener en cuenta, y es la siguiente:

"En este contexto, quienes incurren en el delito de omisión del agente retenedor o recaudador por no consignar las contribuciones parafiscales del Sistema de Seguridad Social en Salud, son las personas naturales que, dentro de las empresas promotoras, han sido encargadas de esas obligaciones en los términos del inciso $3^{\circ}$ del Artículo 402 del Código Penal del 2000. Son esos los verdaderos recaudadores.

También incurren en el delito los intermediarios financieros $u$ otras entidades que firman convenios con las empresas promotoras para el recaudo de las cotizaciones, según las normas reglamentarias que sobre el particular expide el Gobierno Nacional.

$16 \quad$ Ibíd. 
Estos intermediarios asumen la función pública por convenio autorizado por la ley ${ }^{17}{ }^{18}$.

Esta última tesis no es muy compartida por los profesores Gómez Méndez y Gómez Pavajeau, pues consideran que

"La noción de recaudador no puede estar por encima de la noción de servidor público por asimilación, pues aquélla es general o genérica, con aplicación a los particulares dentro del ámbito de las relaciones generales de sujeción, mientras que la calificación de servidor público es específica, propia de las relaciones especiales de sujeción"19.

A pesar de la opinión de los citados profesores, considero importante tener presente el pronunciamiento de la Corte Suprema, pues estamos hablando de personas naturales que aún trabajando para personas jurídicas tienen la obligación de retener las contribuciones parafiscales y consignarlas al sistema de seguridad social; sin embargo, se excluyen de aquellas personas a los empleadores como claramente lo estableció en la siguiente Sentencia:

"La ley 100 de 1993 no le asignó la específica función pública de recaudador al empleador, aunque contribuya o facilite la función de la Entidad Promotora de Salud, descontando al trabajador su parte y girando-pagando-oportunamente al recaudador. La acción típica de recaudar es de carácter legal. La comprensión de su definición y concepto está en las leyes extrapenales que interesan a este asunto, sobre todo la legislación tributaria y la inherente a la salud. $Y$ desde esta normativa se concluye que solamente se realiza este comportamiento rector -recaudar- por asignación de función pública. Su interpretación está limitada por el contenido que le dan la Constitución y la ley. Si no fuera así y se

$17 \quad$ Sobre el particular el parágrafo del Artículo 187 y el Artículo 287 que crea la figura del intermediario.

18 CORTE SUPREMA DE JUSTICIA. Sala Penal. Proceso Radicación 23982. Sentencia del 20 de Julio de 2007. M.P. Álvaro Orlando Pérez Pinzón.

19 GÓMEZ MÉNDEZ, Alfonso, et al. Delitos contra la administración pública. Ob. Cit. p. 97. hiciera la extensión a todo acto consistente en recibir o custodiar dinero, se demeritaría el principio de estricta legalidad de los delitos y de las penas: nullum crimen, nulla poena, nulla mensura sine lege praevia, scripta, stricta, et certa.

(...)

Quede dicho, entonces, que la conducta del empleador particular, que a la fecha o desde la entrada en vigencia de la ley 599 del 2000, descuenta del salario de sus empleados o trabajadores unos aportes para integrar con los suyos la contribución parafiscal al Sistema General de Seguridad Social en Salud, y no los consigna oportunamente, no incurre en el delito de omisión del agente retenedor o recaudador.

Como fue desarrollado por la instancia de segundo grado, la conducta de ese empleador se ubica en el tipo penal de abuso de confianza calificado, definido en el Artículo 250.3 de la Ley 599 del 2000, si fue desplegada en vigencia de este estatuto"20.

La exclusión de los empleadores del delito de peculado es compartida por los profesores Gómez Méndez y Gómez Pavajeau, quiénes consideran que,

"cuando se trata de un empleador que no tiene la calidad de servidor público y como particular no se puede afirmar que administre, tenga o custodie bienes parafiscales, pues simplemente tiene materialmente y casi que de manera instantánea unos dineros que debe remitir a la entidad correspondiente y delegada por el Estado para su administración. En tal caso el delito en que incurre es en un abuso de confianza calificado"21.

Sin embargo, el supuesto que cobija el tipo penal de la omisión del agente retenedor o recaudador es diferente al caso que estamos examinando. La omisión del agente retenedor o recaudador se aplica en aquellos casos en los que un funcionario o gerente de una empresa encargada

20 CORTE SUPREMA DE JUSTICIA. Sala Penal. Proceso Radicación 23982. Sentencia del 20 de Julio de 2007. M.P. Álvaro Orlando Pérez Pinzón.

21 GÓMEZ MÉNDEZ, Alfonso, et al. Delitos contra la administración pública. Ob. Cit. p. 97. 
legal o reglamentariamente de la recaudación de las contribuciones, no las consigna en las cuentas de la respectiva E.P.S., ello incluye a los funcionarios de la E.P.S. que autorizados por ella recibe las contribuciones por parte de un empleador o un trabajador independiente, y nunca los consigna a las cuentas de la E.P.S., o no los reporta a la misma. En este grupo de casos, el dinero nunca ingresa a las arcas de la E.P.S., mientras que el caso que estamos analizando en este trabajo, se trata de dineros que ya entraron a las arcas de la E.P.S. y un empleado o gerente que administrando dichos recursos, se apropia de los mismos.

En todo caso, sin entrar a profundizar en el tipo penal de la omisión del agente retenedor o recaudador -pues no es el tema de este trabajo-, me parece importante resaltar los efectos de la sentencia antes citada, pues los cajeros de una E.P.S. o de un banco que reciban las contribuciones parafiscales de seguridad social y no las consignen a las cuentas respectivas o no reporten el pago, no incurrían en el delito de hurto agravado por la confianza ${ }^{22}$, sino en omisión de agente recaudador.

Hay que señalar igualmente, que la discusión que aquí se ha planteado tiene una gran diferencia en los casos en que los trabajadores se apropien de dineros propios de la E.P.S., es decir, de las utilidades que obtiene ésta por el desarrollo de su objeto social, o de su capital propio como son los equipos o rentas o réditos obtenidos de la venta o arriendo de las instalaciones físicas con las que cuenta, o de los aportes realizados por los socios, toda vez que estos recursos, nunca podrán ser considerados como dineros del Estado, a menos claro está, que hablemos de una E.P.S. pública. En este orden de ideas, si un gerente o empleado se apropia de los dineros que le han sido confiados para su administración y que responden a los conceptos anteriormente señalados, nunca

2 CORTE SUPREMA DE JUSTICIA. Sala Penal. Sentencia de 20 de Mayo de 1986. podrá hablarse de peculado ni de abuso de confianza calificado, sino de abuso de confianza simple, pues se desvirtúan los elementos de la función pública en la administración de recursos del Estado. De tal manera, se hace evidente la necesidad probatoria de determinar el origen de los recursos apropiados de acuerdo con los soportes contables, pues no puede afirmarse irresponsablemente que todos los recursos que maneja una E.P.S. son fondos parafiscales.

\section{ANALISIS CRÍTICO DEL PROBLEMA Y RESULTADO DE LA INVESTIGACIÓN}

\subsection{Planteamiento inicial objeto de la crítica}

Luego del anterior análisis, es claro por una parte que los fondos parafiscales son bienes que le pertenecen al Estado, y por otra que la labor de administrar estos bienes es una función pública. Por este camino, en los casos de apropiación de los recursos provenientes del sistema de seguridad social, se avanza hacia la configuración del delito de peculado pues primero, se configura el concepto de servidor público por extensión establecido en el Artículo 20 del Código Penal, y segundo se encuadran otros aspectos estructurales del tipo de peculado como la conducta (apropiarse), la relación funcional (administración, cuidado o custodia), y el bien (fondos parafiscales).

Sin embargo, dentro de las posiciones antes citadas, parece haber un asunto pendiente que dificulta un poco el tema y es la transmisión de las calidades de servidor público de la E.P.S. al gerente o sus trabajadores. Como bien lo reconocen los profesores Gómez Méndez y Gómez Pavajeau, la calidad de servidor público por extensión, en estricto sentido la adquiere la E.P.S. es decir el ente colectivo -pues es ella la que tiene la función de administrar los fondos parafiscales de conformidad con la $\mathrm{Ley}_{-}{ }^{23}$, por tanto, no sería posible afirmar sin pocas

23 GÓMEZ MÉNDEZ, Alfonso, et al. Delitos contra la administración pública. Ob. Cit. p. 97. 
objeciones, que los trabajadores dentro de los cuales incluyo al gerente o representante legal de una E.P.S. que se apropien de dichos bienes realizarían un peculado, pues no son ellos los que de conformidad con la Constitución, la Ley o el Reglamento asumen la función pública de administrar.

Para solucionar el problema anterior, los profesores citados ${ }^{24}$ plantean como fórmula la teoría del actuar por otro, consagrado en el Artículo 29 inciso 3, para efectos de establecer que un funcionario que actúa en nombre de la E.P.S. se le transfieren las calidades de servidor público que esta detenta, para así poder imputar el delito de peculado en caso de que alguno de ellos se apropie de los fondos parafiscales. A su vez, los citados autores abogan por reconocerles a dichos empleados la rebaja del interviniente establecida en el Artículo 30 inciso 3.

\subsection{En el derecho administrativo la delegación de funciones públicas requiere de un acto formal}

$\mathrm{Al}$ anterior planteamiento se le pueden formular varias objeciones; la primera es que como se dejó sentado en los apartes anteriores, la delegación de las funciones públicas no es un acto informal, pues requiere de la asignación de funciones por parte de la Constitución, la Ley o el reglamento, y los trabajadores de una E.P.S. privada, no tienen calidad de servidores públicos, y ni siquiera el gerente tiene tal calidad, pues su régimen contractual se rige bajo las normas del derecho privado.

El texto del Artículo 20 del Código Penal, que da carácter de servidores públicos a particulares que ejercen permanente o temporalmente funciones públicas, es perfectamente aplicable a las personas naturales que actúan en esas circunstancias, como los conciliadores y árbitros, pues la Ley y la Constitución permiten esa

\footnotetext{
$24 \quad$ Ibídem.
}

posibilidad expresamente. Sin embargo, en los casos en los cuales quién ejerce una función pública es una persona jurídica como en el caso de las E.P.S., esa transferencia de calidad de servidor público, de la empresa a sus empleados debe mediar al menos Ley o Reglamento que así lo permita ${ }^{25}$, es decir, que la Ley o Reglamento debe establecer expresamente que empleados de dicha institución son funcionarios públicos, de conformidad con el texto del Artículo 122 de la Carta que dispone:

"No habrá empleo público que no tenga funciones detalladas en ley o reglamento, y para proveer los de carácter remunerado se requiere que estén contemplados en la respectiva planta y previstos sus emolumentos en el presupuesto correspondiente." $Y$ ello tiene una secuencia lógica, pues al estar ello establecido de esta manera, genera entonces las responsabilidades propias de un servidor público establecidas en el Artículo 6 de la Constitución que dispone: "Los particulares sólo son responsables ante las autoridades por infringir la Constitución $y$ las leyes. Los servidores públicos lo son por la misma causa y por omisión o extralimitación en el ejercicio de sus funciones".

\subsection{No hay necesidad politico criminal para aplicar el actuar por otro}

La segunda consiste en que la figura del actuar por otro regulada en el Artículo 29, tiene una función político criminal específica, pues fue creada para evitar la impunidad en los delitos especiales propios (que requieren sujeto activo calificado) permitiendo la sanción de una persona que no teniendo las calidades exigidas en el tipo penal realiza una conducta punible,

25 Así, por ejemplo, el Artículo 402 del Código Penal, que establece el delito de la omisión del agente retenedor o recaudador, establece: "Tratándose de sociedades u otras entidades, quedan sometidas a esas mismas sanciones las personas naturales encargadas en cada entidad del cumplimiento de dichas obligaciones". Aclarando en todo caso, que el agente retenedor o recaudador son particulares y no servidores públicos. 
actuando en calidad de representante de derecho o de hecho de otra persona natural o jurídica que si reúne dichas calidades, pues se asume la transferencia de las mismas del representado al representante ${ }^{26}$. De esta manera, si la conducta de un empleado que se apropie de bienes parafiscales que administra la E.P.S. con la cual trabaja, queda enmarcada perfectamente bajo el tipo penal del abuso de confianza calificado, no hay impunidad que evitar, y la figura del actuar por otro devendría innecesaria.

No habiendo necesidad político-criminal en el caso estudiado de hacer un traslado de las calidades de la persona jurídica a la persona natural, pues, su conducta no queda impune.

Otro argumento que se podría plantear en contra de la tesis del actuar por otro, es que desde el punto de vista doctrinal la tesis expuesta por los profesores Gómez Méndez y Gómez Pavajeau antes explicada, incurriría en una contradicción conceptual, porque por un lado, traslada la calidad de servidor público que detenta la E.P.S. al empleado, pero luego reconocerle la rebaja del interviniente, aceptando en últimas, que el empleado no tiene las calidades de servidor público que le había transferido.

26 FERRE OLIVE, Juan Carlos, et al. Derecho Penal Colombiano parte general, principios fundamentales $y$ sistema. Ibáñez. Bogotá. 2010. p. 532. VELASQUEZ VELASQUEZ, Fernando. Derecho Penal Parte General. Comlibros. 4 Edición. Medellín. 2009. p. 911-912. BACIGALUPO, Enrique. El actuar en nombre de otro. Curso de Derecho Penal Económico. Marcial Pons. 2 Edición. Ediciones jurídicas y sociales S.A. Madrid. 2005. p. 131-144. BERRUEZO, Rafael. Responsabilidad penal en la estructura de la empresa. Editorial B de F. Montevideo. 2007. p. 108-112. ABELLO GUAL, Jorge Arturo. Responsabilidad penal empresarial. Leyer. Bogotá. 2010. p. 46-53. GONZÁLEZ CUSAAC, José Luis. Las Insolvencias punibles. Temas de Derecho Penal Económico. Trota. Madrid. 2004. p. 99-102. RODRIGUEZ VINDAS, Ramón Luis. Responsabilidad penal de empresas. ¿Societas delinquere potest? Biblioteca jurídica El Dike. Bogotá. 2002. FARALDO CABANA, Patricia. Los delitos societarios. Tirant Lo Blanch. Valencia. No. 55. 1996. GARCIA CAVERO, Percy. Derecho Penal Económico. Tomo I. 2 edición. Grijley. Lima. 2007.
Por lo cual, para evitar los inconvenientes que se han señalado anteriormente, se propone que en vez de imputar peculado en los supuestos estudiados se impute el abuso de confianza calificado, en los siguientes términos: el abuso de confianza calificado se configura según el código penal colombiano, cuando el particular se apropiare de cosa mueble ajena abusando de funciones discernidas, reconocidas o confiadas por autoridad pública. Por lo tanto, podríamos entender que la E.P.S. detentando la calidad de funcionario público por extensión, les confía a sus empleados la función de administrar los fondos parafiscales, y si ellos se apropian de dichos bienes, estarían incurriendo en el abuso de confianza calificado si seguimos esta línea argumentativa.

También podríamos afirmar nuestra postura, utilizando el ejemplo del profesor Tocora antes citado para hacer la siguiente analogía ¿Qué diferencia existiría entre la conducta de una persona a quien el secuestre le da a guardar un bien confiado a él por un juez, a la apropiación que hace un empleado de fondos parafiscales que se le habían entregado por parte de su empleador la E.P.S., para que los administrara? En cambio, podemos encontrar varias similitudes sustanciales, como por ejemplo, que en ambos casos, un funcionario público entrega en administración un bien que se encuentra bajo su custodia; que el particular sigue conservando su calidad de particular; y que la apropiación que realiza se le agrava en virtud de la entidad del bien apropiado.

En estos casos, debe aplicarse la regla general en el derecho de personas esto es, que el patrimonio que entra a las E.P.S. para ser administrado, no entra en la contabilidad de las personas naturales que las conforman, pues se trata de personas jurídicamente diferentes; por tanto, si las personas que se apropian de un bien de la persona jurídica a la que representan, no se están apropiando de sus propios bienes, sino de los bienes de aquella. En el caso bajo estudio, si algún empleado se apropia de bienes que administra la E.P.S., debe 
responder frente ésta y no frente al Estado, pues su relación jurídica laboral es con la E.P.S. y no con el Estado. Ello no excluye, que la E.P.S. deba dar cuentas al Estado de la gestión de los recursos dentro del marco jurídico de las obligaciones contraídas con este.

\subsection{Algunas decisiones de la corte suprema de justicia que fundamentan la tesis}

La tesis expuesta, está debidamente soportada por la jurisprudencia tanto de la Corte Constitucional como de la Corte Suprema de Justicia, como se demostrará a continuación. Por ejemplo, la CORTE CONSTITUCIONAL en Fallo de constitucionalidad de 31 de mayo de 2001, acerca del numeral 2, del Artículo 242 de la Ley 599 de 2000. (M. P. Dr. Jaime Araujo Rentaría) aclaró lo siguiente:

"De acuerdo con la reglamentación legal vigente, en las sociedades nace una tercera persona totalmente independiente de los socios que la componen, esto es, una persona jurídica autónoma sujeto de derechos y obligaciones, con capacidad de goce, capacidad de ejercicio, representación legal y especialmente, que dispone de patrimonio propio.

Si bien es cierto, el patrimonio de la sociedad se encuentra constituido por los aportes de los socios para conformar el capital social, los bienes de la sociedad no son parte de propiedad de cada socio, ni siquiera de manera parcial y no sería aplicable la circunstancia de atenuación punitiva prevista en la norma bajo estudio. Si la conducta recayera sobre uno de los bienes muebles que constituyen el patrimonio de la sociedad legalmente constituida, estaríamos frente al tipo básico de hurto, es decir, "sustracción de bien mueble ajeno", porque el bien mueble pertenece y conforma el patrimonio del ente jurídico autónomo" ${ }^{27}$.

De conformidad con la sentencia antes citada queda claro que aún, si la apropiación se realizara por alguno de los socios, no puede existir

27 En igual sentido: CORTE SUPREMA DE JUSTICIA. Sala Penal. Sentencia del 17 de Septiembre de 2008. M.P. Julio Enrique Socha Salamanca. confusión entre el patrimonio de la sociedad y el patrimonio del socio.

En este otro fallo que también afirma la tesis que aquí se sostiene, la Corte Suprema de Justicia estableció que el gerente de una sociedad podría realizar abuso de confianza y no hurto agravado por la confianza:

"... en éste específico asunto concurre en el procesado la condición de asociado de la firma "PROCESO DIGITAL Ltda.", así como la de representante legal de ésta, pues, desde su creación hasta cuando se resolvió disolverla, ostentó el cargo de gerente en desarrollo del cual le correspondia según la ley $y^{28}$ y los estatutos de la misma ${ }^{29}$, la administración de sus bienes y negocios, y ejecutar todos los actos y contratos comprendidos dentro del objeto social o relacionados directamente con la existencia y el funcionamiento de esa sociedad "sin limitaciones respecto de la cuantía".

Es que, necesario es recordarlo, aun cuando una sociedad comercial está revestida de personería jurídica que le permite ejercer derechos y contraer obligaciones en desarrollo de su objeto social y le da capacidad de ser representada judicial y extrajudicialmente, esas facultades no puede hacerlas efectivas por sí misma por tratarse de una ficción jurídica, $y$ en consecuencia le es indispensable valerse de una persona fisica encargada de manejar, gobernar y dirigir los negocios y bienes de aquella, para proteger el patrimonio y los intereses sociales, persona fisica que en el presente caso no era otra que su representante legal, en quien se encarnaban aquellas prerrogativas dentro de los límites señalados en los estatutos.

De suerte que como el implicado detentaba el cargo de gerente, representante legal de la tantas veces citada sociedad, el cual le confería la administración (comprendidas, naturalmente, en ella las labores de custodia y conservación) jurídica y material de los

28 CÓDIGO DE COMERCIO. Artículos 110 (numeral 12), 196, y 358 (numeral 5). Ley 222 de 20 de diciembre de 1995, Artículos 22 y 23

29 Cfr. Cuaderno original $N^{\circ} 1$. Folios 12 a 19. Escritura Pública $\mathrm{N}^{\circ} 914$ de 5 de mayo de 1993. Artículo decimoctavo. 
bienes y derechos que integraban el patrimonio de la referida empresa, si incurrió en un comportamiento doloso orientado apoderarse, en provecho propio o de un tercero, de todos o parte de aquellos, la conducta punible que su obrar habría materializado no sería propiamente la de hurto agravado por la confianza, sino la de abuso de confianza"so.

Y por último, existe otra Sentencia de la Corte Suprema de Justicia que soporta de mayor forma la posición aquí expuesta, en la cual, estableció que existía abuso de confianza calificado, en un caso en que una compañía de carácter privado había suscrito un contrato con una entidad pública para recaudar los pagos de un servicio por ésta prestada:

"Tamayo González Nuevo Mundo \& Cía Ltda, que tenía como socio mayoritario al hijo de la acusada, adquirió el compromiso a través de su representante legal Luis Alfonso Vélez Better de recaudar los dineros provenientes del pago de servicios públicos de los suscriptores de EADE S.A. E.S.P. en los municipios antioqueños de Arboletes y San Juan de Urabá.

Para el efecto, en el respectivo contrato administrativo-el número 7.871 del 14 de febrero de 2001-, se estableció que la cancelación de las facturas por parte de los usuarios tendría ocurrencia en las oficinas de Tamayo González en dichos municipios todos los días de la semana entre las 8 A.M. y las 6 P.M. y se determinaron los procedimientos a seguir por parte de los cajeros, el relativo al control diario de los pagos e igualmente los días de consignación de los recaudos en las cuentas de la empresa pública.

La sociedad contratista, según la cláusula $10^{a}$ del convenio, debia trasladar los dineros a EADE en una sola consignación, así:

"El día lunes de cada semana, el recaudo efectuado entre los días sábado y domingo. El día jueves de cada semana, el recaudo efectuado entre los días lunes a miércoles. Y el día sábado de cada semana los recaudos efectuados entre los días jueves $y$

30 CORTE SUPREMA DE JUSTICIA. Sala Penal. Sentencia del 17 de Septiembre de 2008. M.P. Julio Enrique Socha Salamanca. viernes, tanto en Arboletes como en San Juan de Urabá". (...)

Significa lo anterior que el papel de Tamayo González era simplemente el de recibir los pagos de las facturas y trasladarlo a EADE casi inmediatamente. Mientras lo hacía, tenía el deber de guardar esos recursos, que no habia obtenido por un título traslativo de dominio, que seguían siendo de EADE, que desde luego mantenian su carácter de bienes públicos y frente a los cuales es manifiesto que no tenía poder de disposición porque los conservaba a titulo de mera tenencia.

Es como entendieron las instancias el caso y por esa razón condenaron a la procesada por la conducta punible de abuso de confianza, calificado por cometerse sobre bienes pertenecientes a una empresa respecto de la cual el Estado tiene la mayor parte. (...)

Era transparente para ella que los valores recaudados como consecuencia del contrato con EADE no le pertenecían a Tamayo González-de la cual era mucho más que una empleada, dicho sea de paso-, que eran de EADE y que estaba obligada a consignárselos tres veces por semana. Al disponer de ese dinero para solucionar problemas económicos de la compañia o para lo que fuera, por lo tanto, se apropió de recursos públicos cuya custodia le había sido confiada y resultó acertado en esa medida atribuirle el cargo de abuso de confianza calificado por la circunstancia $3^{a}$ del Artículo 250 de la ley 599 de 2000"31.

Esta última sentencia, plantea un elemento muy importante, un particular no pierde su carácter de tal, cuando recibe dineros públicos, y de apropiarse de ellos, incurriría en el delito de abuso de confianza calificado.

\subsection{Toma de postura}

Ahora, cabe aclarar que nuestra posición es que tanto los socios, gerentes y trabajadores que administran dichos recursos, o tienen

31 CORTE SUPREMA DE JUSTICIA. Sala de Casación Penal. Proceso No 23201. Sentencia del 12 de Octubre de 2006. M.P. Yesid Ramírez Bastidas. 
responsabilidad sobre ellos, responderían por abuso de confianza calificado. Respecto de los primeros, la jurisprudencia anteriormente citada permite afirmar el supuesto, y la doctrina entre ellos, Molina Arrubla ${ }^{32}$, Muñoz Conde ${ }^{33}$ y Martínez Buján ${ }^{34}$, también son partidarios de esta tesis, y por ejemplo, Candido Conde Pumpido Ferrero ${ }^{35}$, explican claramente que "los administradores sociales, incluido los socios de las sociedades colectivas (...) pueden cometer apropiación indebida de hacer suyos o distraer efectos o cosas muebles que sean objeto de su administración, ..." En los mismos términos, el Tribunal Español estableció "en la STS de 26 de febrero de 1998 (caso Argentia Trust) se considera que aunque no quede probada la apropiación en beneficio propio de 600 millones pertenecientes a la sociedad, el administrador que dispuso de ellos, sin que quede constancia de haberlos reintegrado a la sociedad, comete apropiación indebida...".

En relación con los trabajadores que administran bienes de la E.P.S. quiero citar el fundamento de un trabajo anterior ${ }^{36}$, en el cual se señaló la necesidad de permitir que los trabajadores de una empresa que se apropiaran de bienes que de acuerdo con sus funciones laborales debían administrar (bajo la modalidad de

32 MOLINA ARRUBLA, Carlos Mario. Responsabilidad penal de los administradores de empresa. Biblioteca E1 Dike. Universidad Católica de Colombia. Bogotá. 2006. p. 511-513.

33 MUÑOZ CONDE, Francisco. Derecho Penal parte especial. Tirant Lo Blanch. 15 Edición. Valencia. 2008. p. $442-447$.

34 MARTÍNEZ-BUJAN PÉREZ, Carlos. Administración Fraudulenta en sociedades de inversión. Temas de Derecho Penal Económico. Trota. Madrid. 2004. p. 41

35 CONDE PUMPIDO FERRERO, Candido. Apropiaciones indebidas. Tirant Lo Blanch. Valencia. 1997. p. 96.

36 ABELLO GUAL, Jorge Arturo. "El abuso de confianza y el hurto agravado por la confianza en la responsabilidad penal empresarial en Colombia". En: Revista Prolegómenos Derechos y Valores. Vol XIII. Enero - Junio de 2010. p. 181-200. encargo fiduciario), fueran sancionados por la comisión del delito de abuso de confianza y no de hurto agravado por la confianza que tiene una pena mayor. Este argumento se soporta, pues al gerente de conformidad con la doctrina y jurisprudencia consultada ${ }^{37}$ se le imputa abuso de confianza por la misma conducta, por tanto, en mi concepto debía dársele igual tratamiento al trabajador, pues en últimas, ambos gerente y trabajador, son empleados de la empresa y de conformidad con sus funciones pueden llevar ambos un encargo fiduciario sobre los bienes de la misma, y en caso de apropiarse de ellos, ambos incurrirían en el delito abuso de confianza, y no en el de hurto agravado por la confianza $^{38}$. Ello también se fundamento en la aplicación de una la analogía en bona parte y del principio de favorabilidad para beneficiar al trabajador.

37 MOLINA ARRUBLA, Carlos Mario. Responsabilidad penal de los administradores de empresa. Ob. Cit. p. 511-513. MUÑOZ CONDE, Francisco. Derecho Penal parte especial. Ob. Cit. p. 442-447. MARTÍNEZBUJAN PÉREZ, Carlos. Administración Fraudulenta en sociedades de inversión. Ob. Cit. p. 41-48. TRIBUNAL SUPREMO ESPAÑOL. Sentencia de 26 de febrero de 1998 (caso Argentia Trust). CORTE SUPREMA DE JUSTICIA. Sala Penal. Sentencia del 17 de Septiembre de 2008. M.P. Julio Enrique Socha Salamanca.

38 Sobre la diferencia entre abuso de confianza y hurto agravado por la confianza consultar las siguientes sentencias: CORTE SUPREMA DE JUSTICIA. Sala Penal. Sentencia de 20 de Mayo de 1986. CORTE SUPREMA DE JUSTICIA. Sala Penal. Auto de 26 de junio de 1997. Radicación No 13139. CORTE SUPREMA DE JUSTICIA. Sala Penal. Sentencias de 24 de enero, 7 de marzo y 6 de septiembre de 2007, radicaciones $\mathrm{N}^{\mathrm{o}} 22412,24793$, y 23719 respectivamente. CORTE SUPREMA DE JUSTICIA. Sala de Casación Penal. Casación del 17 de febrero de 1999. Radicado No. 11093. También en las siguientes sentencias: CORTE SUPREMA DE JUSTICIA. Sala Penal. Sentencia del 17 de Septiembre de 2008. M.P. Julio Enrique Socha Salamanca. CORTE SUPREMA DE JUSTICIA. Sala Penal. Proceso No. 33173. Sentencia del 7 de Abril de 2010, M.P. Alfredo Gómez Quintero. CORTE SUPREMA DE JUSTICIA. Sala Penal. Proceso No 27319. Sentencia del 6 de Septiembre de 2007. M.P. Augusto Ibáñez Gúzman. 
Abierta la anterior posibilidad, tanto el gerente, socios y trabajadores incurrirían en abuso de confianza calificado, si se apropian de dineros provenientes de fondos parafiscales que le sean confiados por la E.P.S. que es la que realmente tiene la calidad de servidor público. Y ello debería ser así, pues el abuso de confianza calificado lo dispone de esa manera, y es la ley especial en ese caso concreto. Precisamente, en materia de concurso de tipos, uno de los criterios que permite eliminar la concurrencia entre dos tipos penales, es la especialidad, de tal manera como comenta el profesor Fernando Velásquez, "cuando un supuesto de hecho reproduce los elementos típicos de otro más general, y caracteriza de manera más precisa al hecho o al autor añadiendo elementos adicionales, es este el que se aplica y no aquel" 39 . En otra obra exalta el mismo autor que "según este principio una acción sólo se debe subsumir en aquel de los tipos penales que, de manera más exacta, se adapte a ella y ese proceso mental supone el empleo de criterios tanto de orden lógico como valorativo". En el mismo sentido, la Ley 57 de 1887 establece en su Artículo 5, que "si en los códigos que se adoptan, se hallaren algunas decisiones incompatibles entre sí, se observarán en su aplicación las reglas siguientes: La disposición relativa a un asunto especial prefiere a la que tenga carácter general".

Nuestra tesis también es respetuosa del Artículo 29 de la Constitución Nacional que establece que en materia penal se debe aplicar la Ley más favorable; por tanto, entre el abuso de confianza calificado y el peculado, debe aplicarse por mandato constitucional la norma más favorable que es la del abuso de confianza calificado, pues la pena establecida para esta conducta es de 3 a 6 años, mientras que el peculado tiene una pena de 6 a 15 años. Aún, si retomamos la tesis expuesta por los profesores Gómez Méndez y Gómez Pavajeau, en la cual se concede la rebaja punitiva del interviniente, esto es

39 VELÁSQUEZ VELÁSQUEZ, Fernando. Manual de derecho Penal. Parte general. Ediciones jurídicas Andrés Morales. 4 Edición. Bogotá. 2010. p. 640. en una cuarta parte de la pena del peculado, y al aplicar el Artículo 60 del Código Penal, que determina que dicha rebaja deberá aplicarse tanto al mínimo como al máximo, la pena del peculado con la rebaja del interviniente quedaría en años en 4 años y seis meses a 11 años y 3 meses, esto quiere decir que los topes máximos y mínimos de la pena del abuso de confianza calificado siguen siendo menores y por lo tanto más favorables.

Los resultados punitivos de uno y otro delito, exigen la aplicación de la Ley más favorable para el $\mathrm{reo}^{40}$, de acuerdo con ello y con el principio pro homine, para la interpretación de las leyes restrictivas, se debe aplicar la que menos perjudique los derechos del hombre ${ }^{41}$. En igual sentido se respeta el principio de estricta legalidad, toda vez que no se extiende ilimitadamente la noción de servidor público, a personas que ejerciendo como trabajadores de una E.P.S. -que cumple una función pública-, administren los bienes que esta debe destinar a la salud, pues se trata como describe el abuso de confianza calificado de una función confiada por autoridad pública, y no directamente del ejercicio de una función pública como lo exige el peculado. Es decir, los trabajadores reciben los recursos de las E.P.S. en virtud de las normas de derecho privado (mandato, encargo fiduciario, establecidas en su contrato

40 CONSTITUCIÓN POLÍTICA DE COLOMBIA. Artículo 29-3: Pacto Internacional de derechos civiles y políticos. Artículo 15: Convención Americana de Derechos Humanos. Artículo 9. Código de Procedimiento Penal Artículo 6. Ley 153, Artículos 40 a 44. CORTE CONSTITUCIONAL. Sentencias T-272 de 17 de marzo de 2005 y T-1057 del 6 de diciembre de 2007. CORTE SUPREMA DE JUSTICIA. Sentencia del 3 de septiembre de 2001. Radicado No. 16837.

${ }^{41}$ MIR PUIG, Santiago. Derecho Penal parte general. Editorial B de F. 7 Edición. Montevideo. 2007. p. 116. FERNÁNDEZ CARRASQUILLA, Juan. Derecho Penal Fundamental 1. Ibáñez. 3 Edición. Bogotá. 2007. p. 237-238. VELÁSQUEZ VELÁSQUEZ, Fernando. Manual de derecho Penal. Parte general. Ob. Cit. p. 287-288. 
de trabajo), y no en virtud de las normas de derecho público, es decir no media resolución $o$ acto administrativo.

Por último, se hace necesario señalar que ni siquiera a través de un contrato público con el Estado, un particular se convierte en un funcionario público, pues como ya lo ha establecido la Corte Constitucional, "los contratistas, como sujetos particulares, no pierden su calidad de tales porque su vinculación jurídica a la entidad estatal no les confiere una investidura pública, pues si bien por el contrato reciben el encargo de realizar una actividad o prestación de interés o utilidad pública, con autonomía y cierta libertad operativa frente al organismo contratante, ello no conlleva de suyo el ejercicio de una función pública" ${ }^{42}$. En la misma sentencia también se aclara que "lo que coloca al particular en la situación de servidor público, no es concretamente el vínculo que surge de la relación, importante o no, con el Estado, sino la naturaleza de la función que se le atribuye por ministerio de la Ley" ${ }^{\prime 3}$. Con fundamento en lo dicho por la Corte Constitucional, el profesor Sanguino afirma que "sólo en la medida en que el Estado a través de un contrato asigne a un particular el cumplimiento de una función pública en estricto sentido-entendida ella como toda actividad dirigida a cumplir unos de los fines propios e inherentes al Estado- ese particular se transforma en servidor público y asume correlativamente las responsabilidades públicas consiguientes" 4 .

Existen dos sentencias más de la Corte Suprema de Justicia Sala Penal; la primera es la del 23 de Enero de 1991, y la segunda de 9 de mayo de 2007, que reafirmar la postura de la Corte Constitucional, en el sentido de que un contrato estatal puede eventualmente concebirse como un acto de delegación de funciones públicas a

42 CORTE CONSTITUCIONAL. Sentencia C-563 de octubre de 1998.

43 Ibíd.

44 SANGUINO MADARIAGA, Alirio. Delitos contra el patrimonio económico en la jurisprudencia. Librería Jurídica Sánchez R. Ltda. 2 Edición. Medellín. 2010. p. 477-478. los particulares por parte del Estado, y para ello es necesario primero tener en cuenta la naturaleza del objeto contractual y la prestación que va a realizar el contratista, y segundo de la naturaleza de las funciones de la entidad con la que contrata, toda vez que si el objeto contractual contiene el ejercicio de una función pública, pues se entiende que es un particular que ejerce función pública, y si la institución con la que se contrata utiliza al contratista para la ejecución de políticas públicas propias de su función ${ }^{45}$, se entiende también que existe una delegación de funciones públicas. Sin embargo, cabe aclarar que los anteriores pronunciamientos se refieren a contratos públicos y no a contratos privados.

Este último razonamiento nos lleva a concluir, primero, que al no existir ningún vínculo entre el Estado y el trabajador de una E.P.S., no es posible predicar una delegación de la función pública. Segundo, al no existir un acto formal de delegación de funciones como la Ley, el reglamento, o contrato con el Estado, no se puede asumir una delegación de la función pública en virtud del principio de legalidad que rige esta materia, ni a los trabajadores ni al gerente, que se encuentran vinculados a través de contrato de trabajo o contrato de prestación de servicios o contrato de mandato, regidos todos por el derecho privado. Tercero, las actividades que llevan a cabo los gerentes y trabajadores en relación con la destinación de los recursos de las E.P.S. se diluyen en diversas actividades y labores (contratación de servicios públicos, de personal, compra de medicamentos, utensilios, viáticos, transporte, inversiones, asesorías, etc.)

$45 \quad$ En la Sentencia de la Corte Suprema de Justicia del 9 de Mayo de 2007, esta corporación, condenó a un contratista por apropiarse de un anticipo dado para la construcción de un puerto fluvial, obra contratada por el Ministerio de Transporte. En este caso, consideró la Corte que como el Ministerio de Transporte debe mantener y crear las vías y medios de transporte, el particular que contrató con dicha entidad estaba ejerciendo las funciones públicas que le corresponden al Ministerio de Transporte, y que le fueron delegadas a través del contrato. 
que pierden su esencia pública, partiendo del hecho de que no todos los recursos que maneja una E.P.S. provienen de las contribuciones parafiscales, y la mayor parte de las actividades que realizan son de tipo comercial; por lo tanto, podríamos concluir que realizar una actividad o prestación de interés o utilidad pública como lo es la prestación del servicio de salud, con autonomía y cierta libertad operativa frente al organismo contratante, no conlleva siempre el ejercicio de una función pública, y menos si no se tiene la calidad de servidor público.

El tema se puede mostrar desde el punto de vista práctico: es función del Estado la prestación del servicio de salud, que a través de la Ley se la delega a las E.P.S., quienes asumen dicha función de manera reglada y bajo su propio riesgo. La prestación del servicio de salud se garantiza a través de unas contribuciones obligatorias que deben hacer todos los afiliados al sistema, a través de las E.P.S., recursos que deben ser destinados por éstas a la prestación del servicio de salud. De esta manera, se puede establecer que el abuso de confianza calificado es más conveniente jurídicamente en los casos en que un trabajador de una E.P.S. se apropie de los recursos que esta administra para el sector salud que el peculado, pues por un lado, los trabajadores no tienen ningún vinculo jurídico con el Estado, ni han recibido por delegación directa de este alguna función pública y por otro lado, las pérdidas que sufra la E.P.S. por la comisión de delitos en su contra, en ejercicio de su actividad comercial las asume ésta y no el Estado, solo que la importancia de los recursos de la salud en una sociedad motivan la necesidad de agravar la pena, como bien lo dispone el abuso de confianza calificado.

\section{CONCLUSIONES}

Este trabajo ha arrojado como conclusiones las siguientes líneas argumentativas:

Los gerentes, socios y trabajadores de una E.P.S., se encuentran encargados de administrar las contribuciones parafiscales destinadas al sector salud. Sin embargo, la función pública de recaudar y administrar dichos bienes es una obligación que adquiere la E.P.S. con el Estado, y no las personas jurídicas que conforman una E.P.S.

El ejercicio de una función pública no puede ejercerse sin que medie autorización de la Constitución, la Ley, reglamento o convenio, de tal manera, que el ejercicio de la función pública de administrar las contribuciones parafiscales del sistema de seguridad social, es ejercida por la E.P.S., a través de sus trabajadores y gerentes, sin embargo, éstos no reciben un mandato de administración de acuerdo con las normas del código contencioso administrativo, sino conforme a las normas de derecho privado, esta situación puede determinar que la naturaleza de relación jurídica entre el trabajador y el bien, no sea la misma que entre un funcionario y un bien del Estado.

Que la figura del actuar por otro, que busca evitar la impunidad en los delitos especiales propios como el peculado, permitiendo que a los trabajadores de la E.P.S. se les traslade la calidad de funcionario público que detenta esta, carece de necesidad político-criminal, pues la conducta de apropiación que pueden realizar los trabajadores sobre fondos parafiscales, estaría enmarcada dentro del abuso de confianza calificado y no quedaría impune.

Que frente al principio de legalidad, es más favorable imputar a los trabajadores de una E.P.S. que se apropien de fondos parafiscales que ésta administra, la conducta de abuso de confianza calificado que la de peculado por apropiación. En igual sentido, se respeta la finalidad y la descripción del abuso de confianza calificado establecida por el legislador al eliminar el peculado por extensión y tipificar el delito de abuso de confianza calificado, esto es, castigar a un particular por la apropiación de dineros del Estado. Y por último, se puede también argumentar que el abuso de confianza 
es el tipo penal más especial en el caso concreto, esto es aplicando el criterio de la norma más especial se eliminaría la posibilidad del concurso entre el abuso de confianza calificado y el peculado por apropiación, definiendo la controversia a favor del primero por ser el tipo penal que abarca toda la conducta realizada.

\section{BIBLIOGRAFÍA}

Abello Gual, Jorge Arturo. "El abuso de confianza y el hurto agravado por la confianza en la responsabilidad penal empresarial en Colombia". En: Revista Prolegómenos Derechos y Valores. Vol XIII. Enero - Junio de 2010.

\section{Responsabilidad penal empresarial.}

Leyer. Bogotá. 2010.

BACIGALUPO, Enrique. El actuar en nombre de otro. Curso de Derecho Penal Económico. Marcial Pons. 2 Edición. Ediciones jurídicas y sociales S.A. Madrid. 2005.

BERRUEZO, Rafael. Responsabilidad penal en la estructura de la empresa. Editorial B de F. Montevideo. 2007.

CONDE PUMPIDO FERRERO, Candido. Apropiaciones indebidas. Tirant Lo Blanch. Valencia. 1997.

FARALDO CABANA, Patricia. Los delitos societarios. Tirant Lo Blanch. Valencia. No. 55. 1996.

FERRE OLIVE, Juan Carlos, et al. Derecho Penal Colombiano parte general, principios fundamentales y sistema. Ibáñez. Bogotá. 2010.

FERNÁNDEZ CARRASQUILLA, Juan. Derecho Penal Fundamental 1. Ibáñez. 3 Edición. Bogotá. 2007.

GARCíA CAVERO, Percy. Derecho Penal Económico. Tomo I. 2 edición. Grijley. Lima. 2007.

GÓMEZ MÉNDEZ, Alfonso, et al. Delitos contra la administración pública. Universidad Externado. 3 Edición. Bogotá. 2008.
GONZÁLEZ CUSAAC, José Luis. Las Insolvencias punibles. Temas de Derecho Penal Económico. Trota. Madrid. 2004.

MARTÍNEZ-BUJAN PÉREZ, Carlos. Administración Fraudulenta en sociedades de inversión. Temas de Derecho Penal Económico. Trota. Madrid. 2004.

MIR PUIG, Santiago. Derecho Penal parte general. Editorial B de F. 7 Edición. Montevideo. 2007.

MOLINA ARRUBLA, Carlos Mario. Responsabilidad penal de los administradores de empresa. Biblioteca El Dike. Universidad Católica de Colombia. Bogotá. 2006.

Delitos Contra la Administración pública. Leyer. 4 Edición. Bogotá. 2003.

MUÑOZ CONDE, Francisco. Derecho Penal parte especial. Tirant Lo Blanch. 15 Edición. Valencia. 2008.

QUERALT, Juan Martín, et al. Curso de Derecho Financiero y Tributario. Tecnos. 11 Edición. Madrid. 2000.

RODRÍGUEZ VINDAS, Ramón Luis. Responsabilidad penal de empresas. ¿Societas delinquere potest? Biblioteca jurídica El Dike. Bogotá. 2002.

SANGUINO MADARIAGA, Alirio. Delitos contra el patrimonio económico en la jurisprudencia. Librería Jurídica Sánchez R. Ltda. 2 Edición. Medellín. 2010.

TOCORA, Luis Fernando. Derecho Penal Especial. Librería ediciones del profesional limitada. 11 Edición. Bogotá. 2009.

VELÁSQUEZ VELÁSQUEZ, Fernando. Derecho Penal Parte General. Comlibros. 4 Edición. Medellín. 2009.

Manual de derecho Penal. Parte general. Ediciones jurídicas Andrés Morales. 4 Edición. Bogotá. 2010. 


\section{JURISPRUDENCIA}

CORTE CONSTITUCIONAL. Fallo de constitucionalidad de 31 de mayo de 2001, acerca del numeral 2, del Artículo 242 de la Ley 599 de 2000. M. P. Dr. Jaime Araujo Rentería.

. Sentencia C-037 de 2003.

. Sentencia C-181 de 2002.

. Sentencia C-866 de 1999.

. Sentencia C-563 de octubre de 1998.

. Sentencia T-1057 del 6 de diciembre de 2007.

2005. Sentencia T-272 de 17 de marzo de

CORTE SUPREMA DE JUSTICIA. Sala de Casación Penal. Proceso No. 23201. Sentencia de 12 de Octubre de 2006. M.P. Yesid Ramírez Bastidas.

Casación de 17 de febrero de 1999.

Radicado No. 11093.

Sala Penal. Auto de 26 de junio de 1997. Radicado No. 13139.

. Proceso No. 33173. Sentencia de 7 de Abril de 2010. M.P. Alfredo Gómez Quintero.

. Sentencia de 17 de Septiembre de 2008. M.P. Julio Enrique Socha Salamanca.

Proceso No. 23982. Sentencia de 20 de Julio de 2007. M.P. Alvaro Orlando Pérez Pinzón.

Proceso No. 27319. Sentencia de 6 de Septiembre de 2007. M.P. Augusto Ibáñez Guzmán.

. Sentencia de 9 de mayo de 2007.

. Proceso No. 24793. Sentencia de 7

de marzo de 2007.
Proceso No. 22412. Sentencia de 24

de enero de 2007.

Proceso No. 20075. Sentencia de 6

de Agosto de 2003. M.P. Jorge Luis Quintero Milanés.

Sentencia de 17 de marzo de 1994. Sentencia de 15 de Marzo de 1993. Sentencia de 23 de Enero de 1991. . Sentencia de 21 de Noviembre de

1989. Sentencia de 20 de Mayo de 1986. Sentencia de 21 de Febrero de 1958.

1950. Sentencia de 7 de Noviembre de Sentencia de 3 de septiembre de 2001. Radicado No. 16837.

TRIBUNAL SUPREMO ESPAÑOL. Sentencia de 26 de febrero de 1998 (caso Argentia Trust).

NORMAS.

CÓDIGO DE COMERCIO.

CÓDIGO PENAL COLOMBIANO.

CONSTITUCIÓN POLÍTICA DE COLOMBIA.

CONVENCIÓN AMERICANA DE DERECHOS HUMANOS.

PACTO INTERNACIONAL DE DERECHOS CIVILES Y POLÍTICOS.

LEY 828 DE 2003.

LEY 734 DE 2002.

LEY 222 DE 1995.

LEY 100 DE 1993.

LEY 153 DE 1887. 